\title{
Learning Management Systems: Are They Knowledge Management Tools?
}

\author{
doi:10.3991/ijet.v5i1.887
}

\author{
B. A. AbuShawar, and J. A. Al-Sadi \\ Arab Open University, Amman, Jordan
}

\begin{abstract}
The new adventure of online world has helped to improve many domains and sectors. Knowledge management era which originally related to business sector is now required in industry, health, or any institute that needs to manage its knowledge. Education is no exception! The advancement in computers speed and memory, and the growth of Internet usage are behind the inspiration of e-learning approach. In which the computer is used as a medium to deliver and share educational materials and knowledge instead of face-to-face tutoring. This makes education available to any one, any place, and any time as learner need. This paper presents the relationship between knowledge management and learning management system (LMS) that is used in e-learning paradigms. A detailed description of the LMS used at Arab Open University (AOU) is included in this paper. We claim that the most common LMS can be considered as a knowledge management tool.
\end{abstract}

Index Terms-Discussion Forums, e-Learning, Knowledge Sharing, Learning Management Systems.

\section{INTRODUCTION}

The tremendous evolution in information technology (IT) and computers has positive effects in many fields, especially business, education, and industry. Knowledge management (KM) in its origin relates to business sector, and represents the "set of systematic disciplined actions that an organization can take to obtain the greatest value from the knowledge available to it" [1].

From IT people's point of view, knowledge management means use knowledge by computer; this involves a lot of computer branches as: data mining, question answering systems, and natural web interfaces. Townley [2] points out that KM is "an emerging area of IT practice that developed from the disciplines of computer science, library information science, organizational psychology, and management”. KM concerns with collecting, organizing and distributing information in such forms that it can be practically used [3]. Ion [4] assures that the development in IT domain supports KM through increasing storing facilities and updating of the information.

This enlarges the need of knowledge management not only in business domain but to be involved in wide areas such as: cognitive sciences, organization sciences, information sciences, document management, and decision support systems.

At the same time of supporting KM, information technology widespread, the growth of Internet speed, and usage of the internet move learning away from strict formal learning types towards more informal and collaborative learning and sharing [5]. This open horizon to adopt new distance-learning paradigms such as: e-learning, blended learning, and open learning. We can view these new trends as a tree, where distance learning is the root, and other paradigms are the disciplines. Each of which differs in its roles and target users but all have a common goal that is to enable learning any where any time. Although LMS is used in different types of distance learning but it is also used also in regular learning including in class teaching.

Using computers and Internet as knowledge delivery and communication media consequently is known as elearning approach. In this context, knowledge management is defined as "enabling organizational learning and it supports activities including knowledge acquisition, generation, sharing and use" [6]. In order to share knowledge and make it available, the educational institutes use different technologies in which most of it focus on creation virtual learning environment (VLE) or what is also known as learning management system (LMS). VLEs are computerbased environments that are relatively open systems, allowing interactions and knowledge sharing with other participants and instructors and provide access to a wide range of resources hosted on the system [7].

In this paper, we investigate the claim that learning management system is a knowledge management tool based on our experience at Arab Open University; AOU. Section 2 presents knowledge management definitions. The relationship between knowledge management and learning in general and e-learning in specific is discussed in section 3. Section 4 displays infrastructure of e-learning platform used at AOU. Knowledge management against learning management system and conclusion are discussed in sections 5 and 6 consequently.

\section{KNOWLEDGE \& KNOWLEDGE MANAGEMENT DEFINITIONS}

"I shall reconsider human knowledge by starting from the fact that we can know more than we can tell". [8]

According to this, knowledge is defined as what we know; this involves the mental processes of "comprehension, understanding and learning that go on in the mind and only in the mind, however much they involve interaction with the world outside the mind, and interaction with others" [9]. Lee [10] views knowledge as "information combined with user's ability and experience that is used to solve a problem or to create new knowledge".

Earlier in the 1950s Polanyi [8] introduced two forms of knowledge: explicit and tacit knowledge. Duffy [11] presents explicit knowledge as "knowledge that is documented and public, structured, fixed-content, externalized, and conscious". Tacit knowledge is hard to be formalized 
or represented; it involves "intangible factors embedded in personal beliefs, experiences, and values" [12]. Polanyi [8] argues that tacit knowledge is derived from experience, inherited practice and implies values and beliefs. According to Nonaka [13] the key to knowledge creation lies in the mobilization and conversion of tacit knowledge. Nonaka [13] developed his famous model that converts tacit knowledge into explicit one, where individuals can create new knowledge through combining their tacit knowledge with the knowledge of others. This is generated through reading documents from many sources which enable individuals to know what others previously learned; and also through discussing meetings, conversation, and story telling. All of this enables individual to exchange their knowledge, and get benefits from others experience, and then reformulate all these activities into an explicit knowledge.

From academic perspective, explicit knowledge is knowledge that user is aware of and can be formalized and delivered such as textbooks, lecture notes, and video tapes. While tacit knowledge is hard to be formalized or represented, it is something stored in peoples' mind such as: skills developed in class room, in e-learning environment, and the experience and enhancement professors has added to curriculum [4].

Because knowledge management is still a new era, there are different definitions by different writers from different perspectives. $\mathrm{KM}$ is a system and managerial approach to collecting, processing and organizing enterprise-specific knowledge assets [14]. Management implies all processes related to knowledge creation, identification, and sharing [15].

$\mathrm{KM}$ process is composed of six phases: acquire, create, synthesize, share, use to achieve organizational goals, and establish an environment conductive to knowledge sharing. Ernst and Young address four phases KM approach: knowledge generation, knowledge representation, knowledge codification, and knowledge application.

This overlaps with many IT disciplines require the IT interference. IT people are needed to: write code or modify an existent one to satisfy new demands; support system operations; create metadata to organize knowledge; interact with public to help them using knowledge; and to coordinate and guide the assessment of KM activities [2]. The Wikipedia presents that there is a life cycle for knowledge "starting with capture or creation, moving on to use and reuse with the ultimate goal of enriching an organization's capability" [16]. Based on these facts IT intrusion is necessary to manage and use knowledge effectively.

As a result, using knowledge is not free of charge; there are three types of costs associated with knowledge use [17]:

- Availability which concern with getting knowledge to users.

- Accessibility which concern with opening knowledge for use.

- Applicability which concern with using knowledge effectively so knowledge is useful and meet user expectation.

\section{KNOWLEDGE MANAGEMENT \& LEARNING}

Regardless of learning paradigm, Knowledge and learning go hand by hand [18], where knowledge is a state of potential for action in a person, organization, or group [19], and learning is the process of changing in understanding, decision or action.

According to Antonova and other researchers [20] learning is classified into single-loop learning and doubleloop learning. Single-loop learning concerns of "knowhow" in order to solve a specific problem; and doubleloop learning takes care of establishing new paradigms, models or perspectives to override the existent ones. In any educational institute, the main aim is to share knowledge with all parties by delivering required knowledge to participants, provide an easy way for communications between these parties, and finally learn from its experience to develop new applications, abandon obsolete knowledge and continue institute progress process.

We can see a clear relationship between Antonova classification and Nonaka [13] model, where single-loop learning could be considered as "explicit knowledge", and double-loop learning is converting tacit knowledge into explicit one.

In general, educational systems are like KM systems, both involve the creation of useful knowledge from information or data found in available resources [21].

In the following subsections an introduction to the relationship of KM with e-learning and LMS is presented consequently.

\section{A. KM \& e-Learning}

"Learning using electronic means" [22] summarizes what e-learning is all about. Before the Internet, video tapes, TV lessons, and CD-Rom were used to deliver educational contents to participants. Nowadays with the great evolution in Internet speed, e-learning has been reshaped to use different instructional tools and frameworks that enable the communications between different parties in educational process, and facilitate educational content delivery. e-Learning approach offers education in places where it normally does not, extends resources (information) where there are few, expands the learning day and opens the learning place as it connects people, communities, and resources to support learning [23].

However, students not only learn from educational materials, but also through interaction with each others. They learn something from others questions, from chatting in a specific topic, or even by seeing others study hard [24]. For this, e-learning tools are classified into:

- Curriculum tools which support class functions, which involve: curriculum design and online quizzes; file management authentication and authorization; discussion forums, chatting, and emails to provide media of communication.

- Digital library tools that concern with locating resources.

- Knowledge management tools that help learners visually review, capture, or develop knowledge [21].

e-Learning and KM are symptoms of new management style [25]. Morrison [26] stated that both e-learning and knowledge management do same thing in different ways. e-Learning takes educational material, process those mate- 
rials and redesign it in an efficient easy way to deliver it to different parties, while KM delivers raw or less processed knowledge. Rao [27] clarifies that both e-learning and KM issues converge to cope with new paradigms, promoting "doing while learning and learning while doing”.

\section{B. KM \& LMS}

Whenever you hear about e-learning, you will hear about virtual learning environment (VLE), learning management system (LMS), or e-learning platform. All have the same meaning and represent the infrastructure used by e-learning to deliver and share teaching materials. LMS is internet based, software allowing instructors to manage material distribution, assignments, communications and other aspects of instructions for their courses [28].

In recent years, the need for learning management systems to deliver the courses online becomes a significant issue and the market of developing e-learning platforms has seen a great competition between companies. A lot of e-learning platforms products are found as: Blackboard [29], Moodle [30], FirstClass [31], Interact [32] and Sakai [33]. Some institutes develop their own LMS, others adopt an open-source LMS or bought a commercial one.

The way this LMS presents its knowledge is crucial in education process in terms of flexibility, easiness, and usefulness. In this respect knowledge could be classified into informative and communicative knowledge [34]. Informative knowledge is related to teaching modules such as module calendar, lecture notes, assignments, etc. While communicative knowledge is concerned with facilitating communication between different parties as exchange opinions in discussion forums, chat rooms, messages between students-students, student-tutor, tutor-tutor communication.

To achieve a success learning outcomes, e-learning platform should take care off solving real world problem. Each piece of new knowledge must be based on existing knowledge and connects with it, so pre requests on previous knowledge is very crucial

\section{LEARNing MANAgEmnt System USED AT Aou}

Arab Open University was established in 2002 in the Arabic region, and adopted the open learning approach. An open learning system is defined as "a program offering access to individuals without the traditional constraints related to location, timetabling, entry qualifications" [35].The aim of AOU is to attract large number of students who can not attend traditional universities because of work, age, financial reasons and other circumstances. The "open" terminology in this context means the freedom from many restrictions or constraints imposed by regular higher education institutions which include the time, space and content delivery methods.

Freed et al. [36] claimed that the "interaction between instructors and students and students to students remained as the biggest barrier to the success of educational media". The amount of interaction plays a great role in course effectiveness [37]. For this purpose and to reduce the gap between distance learning and regular learning, the AOU requires student to attend weekly tutorials. Some may argue that it is not open in this sense; however the amount of attendance is relatively low in comparison with regular institutions. For example, 3 hours modules which require
48 hours attendance in regular universities, is reduced to 12 hours attendance in the AOU.

In order to give a better service to students and tutor, to facilitate accessing the required material from anywhere, and to facilitate the communication between them, an elearning plat form is needed. AOU has partnerships with the United Kingdom Open University (UKOU) and according to that at the beginning the AOU used the FirstClass system as a computer mediated communication (CMC) tool to achieve a good quality of interaction. The FirstClass tool provides emails, chat, newsgroups and conferences as possible mediums of communication between tutors, tutors and their students, and finally between students themselves. The most important reason behind using FirstClass was the tutor marked assignment (TMA) handling services it provided. However, the main servers are located in the UKOU which influences the control process, causes delays, and totally depends on the support in UKOU for batch feeds to the FirstClass system [38].

To overcome these problems, AOU use Moodle nowadays as an electronic platform. Moodle is an open-source learning management system (LMS) used by educational institutes, business, and even individual instructors to add web technology to their courses. Both students and tutors can access the system from anywhere with an Internet connection. The Moodle community has been critical in the success of the system. With so many global users, there is always someone who can answer a question or give advice. At the same time, the Moodle developers and users work together to ensure quality, add new ,modules and features, and suggest new ideas for development [39], [40]. Moodle also stacks up well against the feature sets of the major commercial systems, e.g., Blackboard and WebCT [41]. Moodle provides many learning tools and activities such as forums, chats, quizzes, surveys, gather and review assignments, and recording grades.

Moodle has been used in AOU mainly to design a well formed e-learning environment which facilitates the interaction among all parties in the teaching process, students and tutors, and more over to integrate the LMS with the student information system (SIS) and the human resource system (HRS) [42]. Moreover, to release students from being restricted to textual learning contents only, learning materials are provided as: textual lecture notes, video lectures by registering lectures using Ms-Producer, and animation presentation through PowerPoint application.

\section{A. LMS Architecture of AOU}

Learning management system is composed mainly of authoring tool (informative) and activities tool (communicative):

Authoring tool is mainly concern of the content, and in charge to publish any material related to educational knowledge such as:

1. Creating files,

2. Adding text,

3. Adding clocks,

4. Connecting to websites related to the course

5. Content management

Activities tool is mainly concern about creation interaction mediums such as:

1. Discussion forums, 

2. Chat rooms
3. Quizzes
4. Messaging system
5. Submitting home works
6. Grading
7. Integrating with WAP technology

\section{B. LMS Users' Classification}

Systems' users could be arranged into 6 categories: administrator, creator, editing-tutor, non-editing tutor, student, and guest as shown in figure 1 where each one has different authorities and roles.

The administrator has an absolute authority as shown in figure 2 to do:

1. Management of authoring services, this includes:

o create course categories (each faculty is considered as a category)

o create course sub-categories (departments inside faculty)

o create course sections with its students and tutors

o create course modules (teaching modules, blocks, lecture notes.)

2. Management of activity service, this include:

0 add discussion forums

0 add chat rooms

0 add messaging system

0 add any required website link

$\mathrm{O}$ add any activity offline or online for any course

3. Management of general services, this includes:

o create new user names for new tutors, students

0 add calendar

0 add any news announcement

Creator could be assigned at category level or course level, he is in charge of:

- Create course sections

- Add students to each section according to registration sheet

- Assign each section to a specific tutor

- Adding course materials such as blocks, glossary, references

- Create the essential communication media as discussion forums, chatting, etc.

Editing-tutor can do all creation activities related to the course level that he is assigned to such as adding: lecture notes, references, assignments, online quizzes, etc.

Non-Editing tutor can use web site as it without any privilege to create new activities. However, he is able to insert grades for assignment quizzes, giving feedback to students, share in the discussion forums, etc.

A student can use the course website and:

- Download files

- Download assignment and re submit it after solving

- Doing online quizzes

- Fill in online questionnaire related to the course or to evaluate tutor

- Of course playing the major role in discussion forums with other students and with his/her tutor.

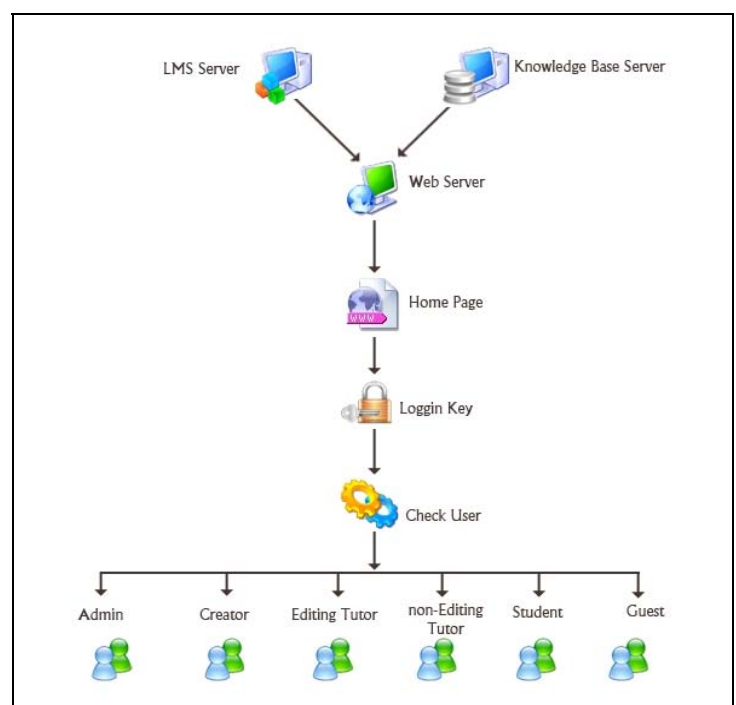

Figure 1. LMS users' classification at AOU

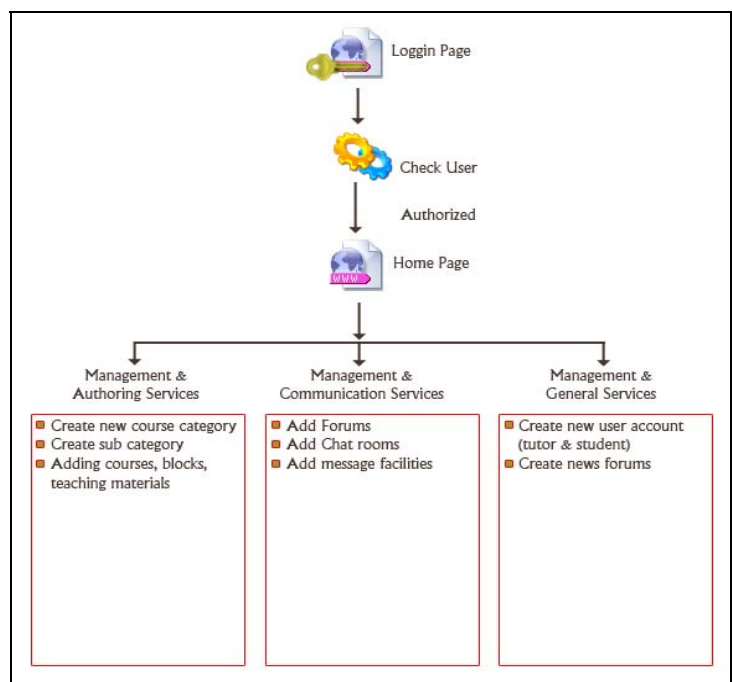

Figure 2. Administrator roles

A guest can observe the activities going on the site depending on his level as course level or category level but he could not do any interaction

\section{The Usefulness of LMS}

The usefulness of the LMS is summarized as follows:

- Simplicity, easy creation and maintenance of courses

- Reuse, support of existing content reuse

- CMC, assignments, test, progress learner involvement

- Security, secure authentication/authorization

- Administration, intuitive management features

- Technical support, active support groups

- Language, true multi-lingual

- Affordability, maintenance and annual charges

- Reducing learning time

- Increased educational retention

- Consistency delivery of content through asynchronous, self placed e-learning 
- Educational knowledge is communicated with good e-learning and knowledge management systems.

- Reducing over all cost associated with tutors salaries, meeting rooms' rental, and student travel.

- On-demand availability of knowledge

- Reducing stress of limited lecture time, so slow or quick learners both will be satisfied

However, there are also some forthcoming problems arise from the fact different LMS has different architecture, which implies the following obstacles:

- Transferring from one LMS to another means recreating to same knowledge again which is a waste of time and effort, unless it is a SCORM compliant.

- Sharing information among systems in distributed universities is difficult

- Sharing student's record in case he/she wants to move to another university which use another LMS

- Comparing LMS systems is complicated since they use different terminologies to describe the same functionalities.

A future and promoted solution is to develop an independent framework which integrates the specification of different platform architectures as described in [43].

\section{LMS VERSUS KM}

This research proposed that: LMS is a KM tool, in order to prove our claim, a comparison between KM and AOU-LMS is presented.

Knowledge sharing is the basis behind knowledge management innovation and transformation, and this sharing is the power of KM [44]. In the same manner, AOU-LMS provides sharing in all levels:

1. Enabling teaching materials to be accessed any where any time is a kind of sharing that provides users (students) with the required explicit knowledge.

2. Providing a communication media between students and tutors though discussion forums is also a media to share experience and ideas which represent the tacit knowledge.

3. Asking users, in this term both professors and students, to fill online questionnaire about teaching strategy, contents, and all available facilities, is also a type of sharing. Where the feedback from those users and their experiences construct the basis to develop and enhance the LMS with new knowledge methodologies, in which the tacit knowledge is converted into explicit knowledge as Nonaka [13] suggested.

4. Send direct message to a specific user via the LMS.

5. The ability to know who are online and to establish chatting with one or more.

Each module in AOU-LMS is sharable through four types of discussion forums (Figure 3):

- News forum is used to announce important dates, such as final exams time table, and other news related to AOU.

- Course forum, is used by the tutor to send lecture notes to all students who are registered in a specific module.

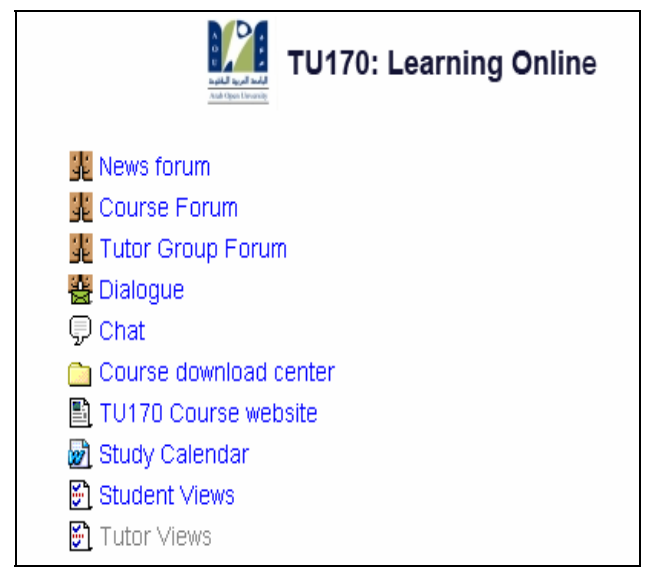

Figure 3. TU170 course (AOU) with its forums

- The tutor group forum is used as an interacting media between tutors and students. Any message send by the tutor in the tutor forum could be accessed by all students registered in this module with this tutor. At the same time, if student send a message to the tutor or to another student, this message could be read by all.

- Dialogue forum, is used to add some privacy in student/tutor relationship, in which messages in these case will be not be accessed by all, only between both parties.

The word "manage" means that the "system provides administrative functions" [45] such as access control, and statistical tools. As overviewed in the previous section, the AOU-LMS provides different authorities to users, in addition to other statistical tools where professors could view their students' marks in an Excel sheet that allows them to present any statistics they need.

Mihalca et al., [22] list four aspects that should be considered in implementing a knowledge management system which are:

- People: knowledge users, knowledge authors, and knowledge analyst. In our case its students, professors, and administrators consequently. For dedicated systems, the role of knowledge analyst is not covered by the administrator; a specialized content management analyst may exist.

- Culture: create a culture where knowledge sharing is the norm. AOU adopts the open learning trend as a culture of teaching, where in this culture sharing knowledge through LMS is the norm.

- Content: creating and managing data, information, and knowledge. This is achieved through professors and administrators of AOU_LMS.

- Technology: technical infrastructure that enables the capture, storage, and delivery of content to those who need it, when they need it. The AOU-LMS is the technological infrastructure used to access educational contents any time any where.

Davenport et al., [46] displays four types of perspectives on knowledge management:

- Creating knowledge repositories that holds knowledge and information in documentary form 
- Improving knowledge access and transfer, this concern with communication issues and the media in which knowledge is accessed and transferred

- Enhancing knowledge environment by integrating knowledge management by other computerized system in the organization.

- Managing knowledge as an asset to organization.

In fact any learning management system is composed of three tiers:

- Knowledge management (Database) tier, which is responsible to deal with knowledge transaction.

- Application tier, which represents the server that makes knowledge available to users and enforce system security.

- Presentation tier, which is the client web browser that makes knowledge accessible to users.

Comparing this 3-tier model of LMS with the above KM perspectives, we find out that LMS covers all these aspects. In terms of integration AOU-LMS with other computerized systems, an in-house enhancement has been done to integrate student information system (SIS) within LMS. This enables students to do registration online, and view their grades (see [43]).

To guarantee success of a knowledge management system, seven factors must be taken into consideration [2]:

1. Identify $\mathrm{KM}$ as priority and encourage participation throughout organization.

2. Train participants how to use it.

3. Using tacit knowledge without any redundancy by using existing data sources first

4. Meet immediate needs of individuals and units.

5. Share knowledge

6. Authorize some people to coordinate overall work

7. Meet any changes in organization philosophy or strategy.

Let us check if these seven points are met within AOULMS:

1. All professors and students at AOU should use LMS as their KM repository. Most assessments are doing via LMS.

2. An induction week is given to all professors before the beginning of the term in order to train them to use LMS, and any new enhancement within it

3. All contents and assessments feedback including grades are collected from LMS, then it could be transformed other systems such as student information system.

4. Using LMS facilitate the student's individual learning capabilities, so each student can learn according to his perception and speed.

5. All materials are available to all students enrolled at AOU according to their modules and sections. Furthermore, students can share their ideas or problems with other students, or their tutor through available forums. All of this can be accessed via the Internet any where any time.

6. LMS has many user categories such as administrator, course creator, and course author. Each category has some privileges as it has been explained in section 2.4 .
7. Many integrations and enhancements of LMS have been done in-house to meet AOU regulations and new strategies. This is a continuous work in improving the LMS.

After all, we believe that AOU-LMS is a knowledge management tool.

\section{CONCLUSION}

Recently, there has been a huge interest of different industries on the new era of knowledge management which become a crucial demand in different sectors. The growing demand on the information technology made huge attention to related domains including knowledge management. On the other side, there was also a huge adventure in the educational domain which has its own revolution from the online industry. The new trend in educational institutes moves towards e-learning. This paper presented the knowledge management from computer industry perspective. Full descriptions of the learning management systems have been also presented including the experience of the Arab Open University of using different LMS. We focused on the role of LMS in general and its capabilities in the area of knowledge management. We hope that this paper contributed new information to fill the gap between the knowledge management and e-learning, specifically the role of the learning management systems as knowledge management tool.

\section{REFERENCES}

[1] A. Marwick. Knowledge management technology. IBM Systems Journals. Vol. 40, No.4, pp. 814-830. 2001

[2] C. Townley. Will the academy learn to manage knowledge?. Educause quarterly. Number 2, pp. 8-11, 2003

[3] C. Bodea, and R. Ion. Knowledge management projects. The AES Bucharest- Revista Militara de Management si educatie, ed. Universitii de aparare nationala Carol, 2006.

[4] A. Ion. Knowledge management and learning. Revista Informatica Economica. No. 4, Vol. 84. PP. 80-83, 2008.

[5] E. Ras, and J. Rech. Bringing together knowledge management and E-learning in software engineering: The Software Organization Platform. [Online]: http://ercimnews.ercim.org/content/ view/264/437/, 2000

[6] A. MacGillivray. Knowledge management in practice: RRU's Elearning platform development. Roads, Royal Roads University's electronic newsletter, 2004.

[7] K. Nagi, S. Charmonman. Evaluating interactivity of elearning resources in a learning management system (LMS)- A case study of MOODLE, an open source platform, 2008.

[8] M. Polayni. The tacit dimension. The University of Chicago Press, 1966.

[9] T. Wilson. The nonsense of knowledge management. Information research, Vol. 8 No. http://informationr.net/ir/8-1/paper144.html, 2002.

[10] H. Lee. Knowledge management and the role of libraries. Chinese Librarianship, Issue 19, pp. 00p. [Online]: http://whiteclouds.com/iclc/cliej/cl19lee.htm, 2005.

[11] J. Duffy. Knowledge management: to be or not to be?. Information management journal 34, no. 1, pp. 64-67, 2000.

[12] SL. Pan, and H. Scarbrough. Knowledge management in practice: an exploratory case study of Buckman Labs Technology Analysis and Strategic Management, Vol. 11, No. 3, pp. 359-374, 1999.

[13] I. Nonaka, and H. Takeuchi. The knowledge-creating company, Oxford University Press, Oxford, UK, 1995.

[14] H. Chen, "Knowledge Management Systems: A Text Mining Approach", http://ai.bpa.arizona.edu/go/download/chenKMSi.pdf, 2001. 
[15] J. Rowley. What is knowledge management? Library Management 20, no. 8, pp. 416-419,1999.

[16] Wikipedia.http://en.wikipedia.org/wiki/Knowledge_management

[17] T. Riley. Knowledge management and technology. International tracking survey report 03, number 2, http://www.rileyis.com/ publications/research_papers, 2003.

[18] A. Bennet, and D. Benne. Organizational survival in the new world, Elsevier, Burlington, 2004.

[19] J. Gavigan, M. Ottisch, and S. Mahroum. Knowledge and learning: towards a learning Europe, Futures report series 14, EC JRC, 1999.

[20] A. Antonova, E. Gourova, and R. Nikolov. Knowledge management and learning in the organizational context. E-learning conference, Portugal, pp. 63-67, 2006.

[21] B. Marshall, Y. Zhang, H. Chen, and A. Lally. Convergence of knowledge management and E-learning: the GetSmart experience (2003) Proceedings of the 3rd ACM/IEEE-CS Joint Conference on Digital Libraries, 2003.

[22] R. Mihalca, A. Uta, A. Andreescu, and I. Intorsureanu. Knolwedge managemt in E-learning systems. Revista Informatica Economica. No. 2, Vol. 46. pp. 60-65, 2008.

[23] A. Arko-Cobbah. The role of libraries in student-centred learning: the case of students from the disadvantaged communities in South Africa, the International Infromation \& Library Review, 36, 263271, 2004.

[24] F. Motoi, H. Yamamoto, D. Shiraki,Y. Faujita, and S. Sakaguchi. An approach to e-learning aimed at knowledge management. In proceeding of 2002 eTEE conference, Switzerlan, 2002, pp. 54-58, 2002.

[25] T. Davenport. G. Probst. KM Case Book, $2^{\text {nd }}$ edition, Publicis Corporate Publishing and John Wiley \& Sons, Erlangen, 2002.

[26] D. Morrison. E-learning strategies, Wiley\&sons, Chichester, 2003.

[27] M. Rao, Knowledge management Toolkit, Prentice Hall, 2005.

[28] Distance education. [Online]: http://alt.uno.edu/glossary.html

[29] Blackboard.http://en.wikipedia.org/wiki/Blackboard_Inc.

[30] Moodle project, Moodle developer documentation. 2006. http://docs.moodle.org/en/developer documentation

[31] FirstClass. http://en.wikipedia.org/wiki/FirstClass

[32] Interact.http://en.wikipedia.org/wiki/Interact_Intranet

[33] Sakai.http://en.wikipedia.org/wiki/Sakai_Project

[34] A. Drigas , and L. Koukianakis. An open distance learning esystem to support SMEs e-enterprising. In proceeding of 5th WSEAS Internationalconference on Artificial intelligence, knowledge engineering, data bases (AIKED 2006). Spain, 2006.

[35] [Online]: www.lmuaut.demon.co.uk/trc/edissues/ptgloss.htm
[36] K. Freed. A History of Distance Learning. Retrieved June 25, 2004. http://www.media-visions.com/ed-distlrn.html

[37] A.P. Rovai, and K.T. Barnum. On-line course effectiveness: an analysis of student interactions and perceptions of learning. Journal of Distance Education, Vol. 18, No. 1, pp 57-73, 2003.

[38] S. Hammad, A.E. Al-Ayyoub, and T. Sarie. Combining existing elearning components towards an IVLE. EBEL conference, 2005.

[39] D. Giannini-Gachago, M. Lee, and D. Thurab-Nkhosi. Towards Development of Best Practice Guidelines for E-Learning Courses at the University of Botswana. In Proceeding Of Computers and Advanced Technology In Education, Oranjestad, Aruba, 2005.

[40] S. Louca, C. Constantinides, and A. Ioannou. "Quality Assurance and Control Model for E-Learning”,.Computers and Advanced Technology in Education. 2004

[41] J. Cole. Using Moodle, O'Reilly. “First edition”, 2005.

[42] B. Abu Shawar. Utilizing AOU’VLE with other computerized systems. International Journal of computer Science and Security (IJCSS). Volume 1, issue 4, pp 13-24, 2007.

[43] Z. Bizonova, D. Ranc, M. Drozdova. Model Driven e-learning platform integration. Telecommunications,. AICT 2007. The Third Advanced International Conference on, 2007.

[44] J. Liebowitz. Knowledge management and its link to artificial intelligence. Expert System with Applications, 20, pp.1-6, 2001.

[45] M. Rochetti, and P. Saini. Knowledge management in an elearning system. In proceedings of the IEEE international conference on Advanced Learning Technologies (ICALT'04), pp. 365369,2004

[46] H. Davenport, D.W. Delong, and M.C. Beers. Successful knowledge management projects. Sloan management review 39, no. 2, pp. 43-57, 1998.

\section{AUTHORS}

B. A. Abu Shawar is with the Information Technology and Computing Department at Arab Open University, P.O.Box 1339 Amman, 11953 Jordan (e-mail: b_shawar@aou.edu.jo).

J. A. Al-Sadi, is with the Information Technology and Computing Department at Arab Open University, P.O.Box 1339 Amman, 11953 Jordan (e-mail: j_alsadi@aou.edu.jo).

Manuscript received 30 March 2009. Published as resubmitted by the authors February 12, 2010. 